\begin{tabular}{|c|c|}
\hline IMAGING AT YOUR FINGERTIPS & carry out in-depth diagnostics, \\
\hline Incorporating the latest 3D imaging & $\mathrm{ng}$ them to \\
\hline technology, Sident Dental Systems' & r diagnostic accuracy \\
\hline new Orthophos XG 3D delivers & and place more implants 'in-house'. \\
\hline excellent image quality, minimum & Similarly orthodontists can use a \\
\hline radiation dose, intuitive software and & cephalometric version to benefit from \\
\hline efficient clinical workflow. It enables & its high quality traditional 2D imaging \\
\hline the operator to switch between $2 \mathrm{D}$ & to identify unerupted teeth and its 3D \\
\hline panoramic and 3D imaging at the touch & capacity to optimise treatment planning. \\
\hline of a button. Optimised for day-to-day & This optional cephalometric module can \\
\hline practice assignments it incorporates & be retro-fitted when desired. \\
\hline height adjustable field of view options & CEREC users can use their CEREC \\
\hline for maximum efficiency. It enables & design data for simultaneous prosthetic \\
\hline clinicians to see more detail and treat & and surgical implant planning. \\
\hline patients more efficiently because it & Whichever option is most appropriate \\
\hline provides more diagnostic benefits and & the fully interactive Easypad touch \\
\hline $\begin{array}{l}\text { better treatment planning capabilities. } \\
\text { Its 3D capabilities are ideal }\end{array}$ & $\begin{array}{l}\text { interface facilitates perfect workflow } \\
\text { and puts the entire spectrum of imaging }\end{array}$ \\
\hline for implant procedures enabling & programs at the user's fingertips. \\
\hline implantologists to generate radiographs, & Reader response number 58 \\
\hline
\end{tabular}

\section{GUARANTEED TO BEAT INSURANCE QUOTES}

As from 17 October 2011, the Post Office is guaranteeing to beat business insurance renewal quotes for dentists' surgeries.

The business insurance policy, which can be accessed from any one of over 11,800 Post Office branches, as well as by phone and online, will provide dentists with access to the wide ranging cover required in the course of their business including:

- Employers' liability insurance up to $£ 10$ million

- Client or staff trips and slips in the workplace

- Computer equipment breakdown
- Loss of gross revenue due to business interruption

- Legal expenses up to £50,000.

The guarantee is valid for all renewals within three months from the 17 October 2011, providing that the business currently has three years' no claims history. Annual premiums must be above quote will be valid for 60 days. The renewal quote must be on an equivalent basis to the Post Office's quote and the offer is available to new Post Office Business Insurance customers only. Reader response number 59 $£ 238.50$ per annum. The Post Office

\section{JOINING FORCES TO BENEFIT DENTISTRY}

Discus Dental was already a thriving and dynamic dental company which had achieved worldwide success with its Zoom chairside tooth whitening system and other innovative oral health technologies and products. However, it was recently acquired by Philips, a company devoted to encouraging greater health and well-being. Oral healthcare is a significant part of its strategy to enhance consumer wellness, and an important growth driver of its product portfolio.

The Discus professional tooth whitening business will strengthen Philips' position as a leading oral healthcare brand amongst dental professionals and consumers. Moreover, the Discus range of oral care products complements the Sonicare portfolio.

Discus Dental has been rebranded as Philips Discus Dental and has a new logo. The Philips stand at the BDTA Dental Showcase in Birmingham in October featured both Sonicare and Discus brands under one umbrella for the first time.

By joining forces the companies can offer dental professionals many benefits: even greater access to some of the UK's thought-leaders, clinical and business consultancy, mentoring and training via one to one meetings, lectures, seminars, countrywide roadshows, articles and a newly launched Transitional Support Programme website portal for newly qualified hygiene-therapists.

\section{Reader response number 60}

\section{FREE EDUCATIONAL LEAFLETS}

Following feedback from the profession, Oral-B has developed a range of educational leaflets. The leaflets explore common questions and issues posed by patients and are not product-focused. One leaflet examines the topic of restorative dentistry, explains the importance of prosthodontic procedures and details the difference between bridges, crowns and implants. Another leaflet explains why regular dental visits are important and illustrates what measures patients should be taking to look after their teeth and gums between appointments. There is also a leaflet on tooth whitening, which clarifies the difference between external and internal staining and the various treatment options available to whiten their teeth. This leaflet includes a section advising patients on the best way to avoid staining in the first place.
The leaflets are available for free to UK dental practices from your local Oral-B representative or, if you prefer an electronic copy, they're available to download from the Oral-B website. Reader response number 61 